\title{
Letting HIV Transform Academia - Embracing Implementation Science
}

\author{
Wafaa M. El-Sadr, M.D., M.P.H., Neena M. Philip, M.P.H., and Jessica Justman, M.D.
}

T he human immunodeficiency virus (HIV) epidemic has had an extraordinary global impact. Even as it has devastated societies, it has also inspired community empowerment, motivated impressive scientific discoveries, and provoked an unprecedented mobilization of vast resources for a single health condition. Not yet fully realized, however, is the epidemic's potential for expanding the core mission of academic institutions to include the pursuit of a wider range of research.

Most universities focus on three core missions: transmitting knowledge to undergraduate students, developing the next generation of scholars through graduate education, and producing new discoveries through research. In both education and research, the past decade has seen dramatic changes. An increasing number of international students are studying at U.S. universities, and a substantial proportion of U.S. students are pursuing international experiences. Online educational initiatives have proliferated, reaching students beyond classroom walls, and several universities have established international centers and branch campuses. ${ }^{1}$ At the same time, research enterprises at universities have grown larger and more complex, with new technologies, use of massive data sets, and growing emphasis on multidisciplinary and interdisciplinary approaches to tackling key scientific challenges.
Universities could foster research in implementation science - the study of methods for improving the uptake, implementation, and translation of research findings into routine and common practice ${ }^{2}$ - to explore the best ways to apply knowledge and discoveries to the challenges facing local and global communities. This is a role, however, that many universities have not yet fully embraced.

The appropriate relationship between the core mission of academic institutions, particularly research universities, and the "real" world has long been a matter of discussion. At his installation on February 3, 1890, for example, the president of Columbia College in New York, Seth Low, articulated his vision of the purpose of the university and academic scholarship, saying, "There is no such thing as the world of letters apart from the world of men. . . . The scholar without this vision is a pedant. He mistakes learning for an end in itself, instead of seeing that it is only a weapon in a wise man's hands." 3 Scholarship, Low believed, should be geared toward the betterment of humanity, and universities should be engaged in solving the practical issues affecting the world around them.

The HIV epidemic is challenging academic institutions to look beyond their traditional core roles and consider how to contribute more fully to the "world of men" - that is, to the public good.
Specifically, the magnitude of this global health threat highlights opportunities for universities to recognize meaningful and scholarly research in implementation science in order to advance the health and well-being of populations around the world.

Of course, researchers at academic institutions have made major contributions to advancing our understanding of the HIV epidemic, including basic research on the pathogenesis of HIV disease; clinical research aimed at the discovery of new diagnostic, prevention, and treatment interventions; and epidemiologic research to identify risk factors associated with HIV transmission. The events that follow this discovery phase, however, have largely been considered beyond the purview of traditional academicians and have been left for entities such as governmental agencies and nongovernmental organizations to tackle. As a result, academic environments often place more value on the discovery itself and less value on learning how to realize the potential benefit of its application.

This disparity also applies to health conditions beyond HIV. Key discoveries remain confined to publications in journals and books, underutilized by the people most in need of them. This lack of use is largely attributable to the limited knowledge about how best to implement and scale up these discoveries. For example, neonatal resuscitation and 
basic emergency obstetrical interventions have been shown to be lifesaving, yet such care remains inaccessible in many resourcelimited settings. Similarly, efficacious tools and interventions for diagnosing and preventing tuberculosis are often underutilized in places where they would have the most impact; such underuse contributes to the unchecked spread of the disease. ${ }^{4}$ If we understood how to implement these ideas in a variety of settings and at scale, they would profoundly to this effort, since it often requires the participation of disciplines already found within academic institutions, including public health, medicine, economics, policy, engineering, and business. Some research in implementation science is in fact occurring within some non-health-related schools and departments, but its full potential has yet to be realized in either non-health-related or health-related areas.

Some observers may raise concerns about this new role for aca-

\section{The HIV epidemic is challenging academic institutions to look beyond their traditional core roles and consider how to contribute}

\section{more fully to the public good.}

affect the health and well-being of populations. But there has been insufficient research on ways of implementing these discoveries with fidelity and, most important, at large scale. ${ }^{3}$

The paucity of implementation research extends beyond the health field. For example, in the field of education, preschool education has been shown to have value, but there has been very little research on how best to implement such programs to achieve the desired short- and long-term outcomes. ${ }^{5}$

We believe this disparity should motivate a reexamination of the type of research valued by academic institutions. Such institutions should recognize two additional related but distinct types of research - research in the implementation of new discoveries and research in the practice of bringing them to scale to achieve meaningful results. Indeed, universities are well suited demia: How will engagement in implementation and scale-up research fit within the academic mission? Are academic institutions prepared to provide the necessary administrative systems and resources to enable successful engagement in this type of work, particularly on a global scale? Will this type of research meet with the same appreciation in academic environments as more traditional discovery research? Since implementation research may be misperceived as intrinsically lacking in rigor, researchers engaged in implementation science will need to distinguish their work with excellence in design and execution.

Although there will inevitably be challenges, we believe that welcoming implementation science and creating a supportive environment for academics who pursue this path carries advantages. Engaging in this broader research framework will accelerate the progress from discovery to scaleup by improving the iterative process that is central to the advance of science. As gaps in knowledge arise during studies of implementation or scale-up, such questions will spark further inquiry by discovery researchers. This cycle has already begun to occur. For example, during the implementation and scale-up of HIV-treatment programs in resource-limited countries, it became clear that simpler methods for monitoring the response to antiretroviral treatment were needed. The need motivated discovery research to develop pointof-care assays for CD4 $\mathrm{T}$ cells. We anticipate that a broader intellectual framework will allow faculty and students to become engaged in the full spectrum of research, enable the application of a rigorous scientific approach to both discoveries and implementation, and lead to more informed policies.

The words of Seth Low remain relevant today, inspiring reflection on the mission of the university in the era of globalization. Academic institutions have an opportunity to embrace societal challenges more fully by placing value not only on discovering the "what" but also on elucidating the "how" and bringing to action discoveries with broad benefits. If the HIV epidemic successfully inspires an expanded academic mission, this transformation could be added to its many lasting legacies.

\footnotetext{
Disclosure forms provided by the authors are available with the full text of this article at NEJM.org.

From the International Center for AIDS Care and Treatment Programs, Mailman School of Public Health, Columbia University, New York.
} 
1. Wildavsky B. The great brain race: how global universities are reshaping the world. Princeton, NJ: Princeton University Press, 2010.

2. Padian NS, Holmes CB, McCoy SI, Lyerla R, Bouey PD, Goosby EP. Implementation science for the US President's Emergency Plan for AIDS Relief (PEPFAR). J Acquir Immune Defic Syndr 2011;56:199-203.

3. Proceedings at the installation of Seth Low, LL.D. as President of Columbia College in the City of New York, February 3, 1890. New York: Columbia College, 1890 (https://archive .org/stream/proceedingsatins00 colurich\# page/n5/mode/2up.|)

4. Jamison DT, Breman JG, Measham AR, et al. Disease control priorities in developing countries. 2nd ed. Washington, DC: World Bank and Oxford University Press, 2006 (https://openknowledge.worldbank.org/ handle/10986/7242).

5. Hirokazu Y, Weiland C, Brooks-Gunn J, et al. Investing in our future: the evidence base on preschool education. Ann Arbor, MI: Society for Research in Child Development, 2013 (http://www.srcd.org/policy-media/ policy-updates/meetings-briefings/investing -our-future-evidence-base-preschool).

DOI: 10.1056/NEJMp1314777

Copyright (C) 2014 Massachusetts Medical Society.

The New England Journal of Medicine 